\title{
Reducing health disparities in underserved communities via interprofessional collaboration across health care professions
}

This article was published in the following Dove Press journal:

Journal of Multidisciplinary Healthcare

2I April 2015

Number of times this article has been viewed

\author{
Allison A Vanderbilt ${ }^{1,2}$ \\ Michael D Dail ${ }^{3}$ \\ Parham Jaberi ${ }^{4}$ \\ 'Center on Health Disparities, ${ }^{2}$ School \\ of Medicine, Virginia Commonwealth \\ University, Richmond, VA, USA; ${ }^{3}$ Family \\ Health Clinic, McDonald Army Health \\ Center, Fort Eustis, VA, USA; ${ }^{4}$ Virginia \\ Department of Health, Chesterfield \\ Health District, Chesterfield, VA, USA
}

Correspondence: Allison A Vanderbilt School of Medicine, Virginia Commonwealth University, 730 East Broad Street, Suite 4II6, Richmond, VA 23298, USA Email avanderbilt@vcu.edu

\begin{abstract}
Health disparities can negatively impact subsets of the population who have systematically experienced greater socioeconomic obstacles to health. Health disparities are pervasive across the United States and no single health care profession can tackle this national crisis alone. It is essential that all health care providers work collaboratively toward the overarching goal of systematically closing the health disparities gap. Interprofessional collaboration is the foundation needed for health care providers to support patient needs and reduce health disparities in public health. Let us reach across the silos we work within and collaborate with our colleagues. Stand up and begin thinking about our communities, our patients, and the future overall health status of the population for the United States.
\end{abstract}

Keywords: health disparities, underserved communities, public health, interprofessional collaboration, community health, health care providers

\section{Introduction}

The overall health status of the population is formed by the summation of communities. In the United States, the health of the population falls on an uneven continuum ranging from healthy to unhealthy and fluctuates based on several variables. Alarmingly, these variables are linked to an enormous gap within the health care system related to health disparities that are commonly associated with a variety of factors including: income, race, ${ }^{1}$ and geographic location. Increasingly, research policy and public health practice literature report substantial disparities in life expectancy, morbidity, risk factors, and quality of life, as well as persistence of these disparities among segments of the population. ${ }^{2-6}$ Health disparities can negatively impact subsets of the population who have systematically experienced greater social or economic obstacles to health.

Obstacles hindering health disparities can stem from a host of characteristics historically linked to discrimination or exclusion such as race or ethnicity, religion, socioeconomic status, sex, mental health, sexual orientation, geographic location, as well as cognitive, sensory, or physical disability. ${ }^{7}$ Researchers, scholars, and health care professionals must caution against the blanket statement of "I am a health disparities expert", because the United States is plagued by inadequate interprofessional collaboration and comprehensive teamwork and is systemically diseased with inequality in health care. Health disparities are pervasive across the United States and no single health care profession can tackle this national crisis alone.

It is essential that all health care professionals work collaboratively toward the overarching goal of systematically closing the health disparities gap within the United States. It must be the duty of health care professionals, physicians, nurses, pharmacists, 
social workers, and researchers to collaborate together in order to reduce health disparities and better the overall health among people within the United States. One proposed way to close this gap is to streamline collaborative efforts by working together under the framework of an interprofessional model with the intended outcome of better results for our patients in underserved communities.

\section{Successful interprofessional health care programs}

Interprofessional health care teams have the potential to become the backbone of how patients are treated when they walk into a free clinic. More specifically, a comprehensive team comprising experts from all health care backgrounds will have the ability to treat the whole patient rather than just the chief compliant. Especially when referring to more complex highly vulnerable patients who are "at-risk" or come from a health disparities background. This means that the patients can have access to the pharmacist, nurse, social worker, physician, and allied health expert all at one central location; therefore, his/her needs can be met from a health perspective. The following are two successful examples of interprofessional health care programs currently in place in Virginia.

One, a student-led organization that was created by VanderWielen et al. ${ }^{8}$ The organization was successfully implemented as an interprofessional education and crossdisciplinary collaboration at Virginia Commonwealth University known as the Inter Health Professional Alliance organization. This group works in underserved communities to provide basic care such as blood pressure and diabetes screening to patients for free and then will share with them resources within their community so they can access care that the "patient" may need. Inter Health Professional Alliance stemmed out of students wanting more interprofessional collaboration and not waiting for faculty to bring them together; the students meet monthly and work together with the common goal of optimizing patient care.

Two, is the International/Inner City/Rural Preceptorship program at Virginia Commonwealth University School of Medicine partners with a local free clinic to provide enhanced teaching practice experience for program participants. ${ }^{9}$ This unique primary care learning experience partners medical students, pharmacy students, interpreters, and a variety of levels of learners to care for diverse patients within two free clinics, with a goal to accommodate the working uninsured. Students are precepted closely by health care professional faculty, are supported by free clinic staff, and are challenged to work effectively on a team while addressing access, socioeconomic, language, and educational barriers.

\section{Barriers to interprofessional health care teams}

Health care professionals in the United States are continuously challenged to provide comprehensive care to their patient populations. ${ }^{8}$ Regrettably, in the United States, health care professionals are taught and/or trained in a format that is disconnected (silo) from interprofessional collaboration and teamwork, thus, leading to a multitude of challenges in practice. ${ }^{10}$ This approach to education produces health care professionals who are more likely to potentially lack interprofessional competence, role clarity, and crucial communication skills required to collaborate efficiently on a health care team. ${ }^{11}$ Health care professionals of various disciplines often find that they work parallel to each other, rather than interactive as a collaborative team. ${ }^{12}$ The composition of the health care team is often unclear, thus, resulting in a health care system that is frequently dispersed, uncoordinated, and lacks true collaboration. ${ }^{5}$ It is the patient who suffers, as the individual health care professionals cannot meet the complex health care needs of the twenty-first century. ${ }^{13,14}$

Many benefits of interprofessional education have been demonstrated in the literature, and implementation of interprofessional programs at the educational level has been severely hindered. The Institute of Medicine's (IOM) seminal 2003 report entitled "Health Professions Education: A Bridge to Quality" called for health care students and working professionals to collaborate on interdisciplinary teams and engage in quality improvement. ${ }^{15}$ Disappointingly, the United States ranks near the bottom among industrialized nations in every quality parameter measure, thus heightening the growing importance of quality care provided within interprofessional teams. ${ }^{8}$ Divisive battles among the health care disciplines have resulted in inhibited collaboration and teamwork. ${ }^{16}$ Kruse argues that health care providers often lack respect for others, fail to recognize the value of a team-based approach and a shared vision, and demonstrate a deficiency in communication skills that are required to set goals and priorities aimed to improve health care efficiency and effectiveness. This health care attitude of solitude exists because we have allowed and even fostered competitive training programs rather than growing a rich environment grounded in interprofessionalism, teamwork, and collaboration. ${ }^{16}$

Interprofessional collaboration is the foundation needed for health care providers to support patient needs ${ }^{17}$ and reduce 
health disparities in public health. Perhaps the most vital venue for implementation is among underserved communities with high needs and vulnerable populations. Therefore, we define interprofessional collaboration as two or more health care providers from different backgrounds collaborating effectively together in order to improve health outcomes for their patients while working with patients, families, and communities to deliver the highest quality of care. Over the past decade, there has been a push toward interprofessional collaboration and teamwork. ${ }^{17}$ Interprofessional collaboration can bring forth the cooperation, communication, and teamwork necessary to provide a comprehensive health care plan to treat and better care for the patients, thus reducing health disparities within communities from all socioeconomic backgrounds. In addition, interprofessional collaboration can lead to an improvement in public health and address social determinants of health using a multidimensional approach to health care. ${ }^{18}$

\section{Call for interprofessional health care teams}

Health care professionals and others advocated for interprofessional collaboration in health care for several decades. ${ }^{19}$ Since 1978, the World Health Organization (WHO) ${ }^{19}$ has promoted collaboration from multiple disciplines that could lead to accessible and affordable health care. It is evident that a collaborative, interprofessional, and a team-based approach to patient care has been highly recommended and discussed for more than 35 years. This can be a potential way to reduce health disparities paired with other known effective medical interventions previously identified. Interprofessional collaboration may assist with reducing health disparities because it brings a comprehensive team (eg, physicians, pharmacists, nurses, social workers, researchers, and so forth) to treat the patient in addition to providing the community as a whole with experts. Finally, this comprehensive team-based approach can bring extensive expertise to the local community that would otherwise not be present; thus, providing additional resources, health care services, and the potential for unexpected positive outcomes for the community.

Over a decade ago, the IOM called upon the international health care community and health education leaders to meet the changing demands of population health by focusing on the development of interprofessional teams. ${ }^{10}$ As evident in the literature, it has been demonstrated that an interprofessional approach to health care can reduce medical errors, hospital readmissions, decrease mortality rates, and improve health outcomes for those with chronic conditions. ${ }^{19}$ Ten years later, universities, hospital systems, and public health agencies are still discussing the importance of interprofessional collaboration; yet, few have truly implemented the vision set forth by the IOM. Therefore, the time is upon us today to challenge our organizations, our leaders, and our institutional systems to assure we are providing the best model of service and health care to our patients. If we want to successfully reduce and begin to prevent health disparities, we must come together as an interprofessional health care team that works collaboratively toward the same goal.

The WHO challenged us over three decades ago, and the time is now - with health disparities on the rise in the United States, let us take this call to action before us and reach across the silos we work within and collaborate with our colleagues. Stand up and begin thinking about our communities, our patients, and the future overall health status of the population for the United States. Together, we can reduce health disparities and slowly close the gap.

\section{Conclusion}

In order to be successful with interprofessional collaborative teams, additional funding sources may not necessarily be the solution; rather, it is more essential that all active participants from various training backgrounds participate to better the health outcomes of the community and/or individual patient. The answer to interprofessional health care teams may be teamwork, time, and effort to the success and striving toward achieving the common goal. Hence, institutions should not shy away from providing the infrastructure necessary to support interprofessional health care teams within the community because it has the potential to save money, provide better health outcomes for patients, and streamline the health care process. Therefore, "true" financial dollars are not being spent on behalf of all agencies to initiate this process; rather, it is embracing the call set forth by the IOM and WHO set forth several decades prior.

This call set forth by the IOM and WHO can be achieved through clerkship rotations, volunteer opportunities, or training programs for students while pursuing their degree, as highlighted by the International/Inner City/Rural Preceptorship program at Virginia Commonwealth University, School of Medicine. Additionally, this can meet the standards set forth by many schools now required by their accreditation agencies. One example is the Liaison Committee on Medical Education requiring both health disparities and interprofessional education as part of the curriculum; ${ }^{20}$ it would be beneficial to both medical schools and other health professional students to increase participation with 
patients within the community. Therefore, interprofessional collaboration health care providers will be a part of the future and a potential solution to reducing health disparities within the United States.

\section{Disclosure}

The authors report no conflicts of interest in this work.

\section{References}

1. Berenson J, Shih A. Higher readmissions at safety-net hospitals and potential policy solutions. Issue Brief (Commonw Fund). 2012;34: $1-16$.

2. Agency for Healthcare Research and Quality. 2009 National Healthcare Disparities Report. Rockville, MD: US Department of Health and Human Services, AHRQ; 2010. [Publication no 10-0004].

3. US Department of Health and Human Services. Healthy People 2010: With Understanding and Improving Health and Objectives for Improving Health. Vol 2. 2 ed. Washington DC: US Government Printing Office; 2000.

4. Keppel KG, Pearcy NJ, Wagner KG. Trends in Racial Ethnic Specific Rates for the Health Status Indicators: United States, 1990-1998. Healthy People 2000. Vol 23. Atlanta, GA: CDC; 2002:1-16. [Stat Notes].

5. CDC/National Center for Health Statistics (NCHS). Healthy People 2000 Final Review. Hyattsville, MD: US Department of Health and Human Services, CDC, NCHS; 2001.

6. Nelson AR. Unequal treatment: report of the Institute of Medicine on racial and ethnic disparities in healthcare. Ann Thorac Surg. 2003;76: 1377-1381.

7. US Department of Health and Human Services. Healthy People 2020 Draft. Washington, DC: US Government Printing Office; 2009.

8. VanderWielen LM, Vanderbilt AA, Dumke EK, et al. Improving public health through student-led interprofessional extracurricular education and collaboration: a conceptual framework for success. $J$ Multidiscip Healthc. 2014;7:105-110.
9. Crossman S. Interprofessional Education and Service: Teaching and Learning with Meaning. Leawood, KS: Society of Teachers of Family Medicine; 2010.

10. Institute of Medicine. Crossing the Quality Chasm: A New Health System for the 21st Century. Washington, DC: National Academies Press; 2001.

11. Interprofessional Education Collaborative. Core Competencies for Interprofessional Collaborative Practice. Washington, DC: Interprofessional Education Collaborative; 2011.

12. Sargeant J, Loney E, Murphy G. Effective interprofessional teams: "contact is not enough" to build a team. J Contin Educ Health Prof. 2008;28(4):228-234.

13. Siple J. Drug therapy and the interdisciplinary team: a clinical pharmacist's perspective. Generations. 1994;18(2):49.

14. Lewis VA, Larson BK, McClurg AB, Boswell RG, Fisher ES. The promise and peril of accountable care for vulnerable populations: a framework for overcoming obstacles. Health Aff (Millwood). 2012;31(8):1777-1785.

15. Institute of Medicine; Greiner A, Knebel E, editors. Health Professions Education: A Bridge to Quality. Washington, DC: National Academies Press; 2003.

16. Kruse J. Overcoming barriers to interprofessional education. Fam Med. 2012;44(8):586-588.

17. Vanderbilt AA, Isringhausen KT, Brownwell PB. Interprofessional education: the inclusion of dental hygiene within the United States - a call to action. Adv Med Educ Pract. 2013;4:227-229.

18. Vanderbilt AA, Isringhausen KT, VanderWielen LM, Wright MS, Slashcheva LD, Madden MA. Health disparities among highly vulnerable populations in the United States: a call to action for medical and oral health care. Med Educ Online. 2013;18:1-3.

19. World Health Organization. Framework for Action on Interprofessional Education and Collaborative Practice. Geneva: World Health Organization; 2010.

20. Liaison Committee on Medical Education. Accreditation Standards; 2015. Available from: http://www.lcme.org/standard.htm. Accessed February 3, 2015.
Journal of Multidisciplinary Healthcare

\section{Publish your work in this journal}

The Journal of Multidisciplinary Healthcare is an international, peerreviewed open-access journal that aims to represent and publish research in healthcare areas delivered by practitioners of different disciplines. This includes studies and reviews conducted by multidisciplinary teams as well as research which evaluates the results or conduct of such teams or

\section{Dovepress}

healthcare processes in general. The journal covers a wide range of areas and welcomes submissions from practitioners at all levels, from all over the world. The manuscript management system is completely online and includes a very quick and fair peer-review system. Visit http://www.dovepress.com/testimonials.php to read real quotes from published authors. 